\title{
ANALISA TROUBLESHOOTING PADA ROTARY CAR DUMPER DAN PENGARUHNYA TERHADAP WAKTU PEMBONGKARAN BATUBARA DI UNIT PELABUHAN TARAHAN PT BUKIT ASAM, Tbk.
}

\author{
THE ANALYSIS OF TROUBLESHOOTING ON ROTARY CAR DUMPER \\ AND ITS IMPACT ON THE COAL DISPOSAL TIME AT \\ TARAHAN PORT UNIT OF PT BUKIT ASAM, Tbk.
}

\author{
Kemas Moh. Ade Isnaeni ${ }^{1)}$, Febri Hariyanto ${ }^{2)}$, Roby Cahyadi $^{3)}$ \\ ${ }^{1,2,3)}$ Program Studi Teknik Pertambangan Batubara Politeknik Akamigas Palembang, 30257, Indonesia \\ Corresponding Author E-mail: ade_presiden@pap.ac.id danfebrihariyanto93@gmail.com
}

\begin{abstract}
PT Bukit Asam, Tbk. is a state-owned company engaged in coal mining sector, coal distribution used train from the mine to Tarahan Port Unit. Tarahan Port Unit was a main port owned by PT Bukit Asam, Tbk. chich provided selling for both domestic and abroad with the distribution by ships or barge. The coal trains were discharged in Tarahan Port by utilizing Rotary Car Dumper 3 . This tool had several troubles and troubleshooting such as ; 1 . Electricity trouble Emergency Stop Relay Trip caused by the too hot electricity panels and could be handled by giving air conditioning in the electricity panels; 2. The indication sensor of apron feeders covered by dust caused by too much dust on the disassembly things and could be overcome by giving water using water spray; 3 . The positioner which stopped not in the right place caused by the error sensors because of refraction and reflection of the wet carriage surface and could be overcome manually by placing the operator assistant in that unit; 4. Waiting for the garbage pickup in the carriages caused by too much garbage in the carriages and could be overcome by handpicking clerk. The cycle time needed for one process of the coal carriage unloading was 2 minutes 54 seconds with unloadingtime of a 60 -series carriages of 87 minutes.
\end{abstract}

Keywords: Rotary Car Dumper, Trouble, Troubleshooting.

Abstrak: PT Bukit Asam, Tbk. adalah perusahaan milik negara yang bergerak di bidang pertambangan batubara, pengiriman batubara menggunakan kereta api dari tambang menuju ke Pelabuhan Tarahan. Unit Pelabuhan Tarahan adalah pelabuhan utama milik PT Bukit Asam, Tbk. yang melayani penjualan dalam negeri maupun luar negeri dengan pengiriman menggunakan kapal atau tongkang. Kereta batubara dibongkar di Pelabuhan Tarahan dengan menggunakan alat yaitu Rotary Car Dumper 3. Alat ini memiliki beberapa trouble dan troubleshooting antara lain : 1. masalah kelistrikan (Emergency Stop Relay Trip) yang di akibatkan panel listrik terlalu panas dan dapat diatasi dengan memberikan pendingin ruangan pada ruangan panel listrik; 2. sensor indikasi apron feeders yang terhalang debu yang diakibatkan bongkaran terlalu banyak debu dan dapat diatasi dengan pemberian air menggunakan water spray; 3. positioner berhenti tidak pada tempatnya yang diakibatkan sensor yang error karena pembiasan dan pemantulan terhadap permukaan gerbong yang basah dan dapat diatasi secara manual dengan menempatkan asisten operator di unit tersebut; 4. tunggu pengambilan sampah di gerbong yang diakibatkan terlalu banyak sampah didalam gerbong dan dapat diatasi oleh petugas handpicking. Cycle time yang dibutuhkan untuk sekali proses pembongkaran gerbong batubara adalah sekitar 2 menit 54 detik dengan waktu pembongkaran satu rangkaian 60 gerbong selama 87 menit.

Kata kunci: Rotary Car Dumper, Trouble, Troubleshooting.

\section{PENDAHULUAN}

\subsection{Latar Belakang}

PT Bukit Asam, Tbk. Unit Pelabuhan Tarahan merupakan pelabuhan batubara yang berada di provinsi Lampung dan merupakan salah satu pelabuhan yang mengirimkan pasokan batubara untuk pembangkit listrik baik untuk memenuhi kebutuhan lokal maupun ekspor. Pelabuhan ini awal nya dibuat untuk memenuhi kebutuhan batubara ke PLTU Suralaya sebagai pembangkit listrik di pulau Jawa dan Bali. Terdapat 3 (tiga) dermaga yang digunakan dengan masing - masing kapasitas sandar 10.000 DWT, 80.000 DWT dan 210.000 DWT. 
Batubara yang diterima di unit pelabuhan berasal dari tambang batubara di PT Bukit Asam Unit Pertambangan Tanjung Enim (UPTE) di daerah Sumatera Selatan. Batubara dibawa menggunakan gerbong kereta api yang memiliki jumlah 60 gerbong tiap satu rangkaian. Dalam satu hari, rangkaian yang diterima oleh Unit Pelabuhan Tarahan sebanyak 17-18 rangkaian kereta batubara. Sebelum masuk ke area PT Bukit Asam Unit Pelabuhan Tarahan, rangkaian kereta terlebih dahulu dicek kesiapannya di stasiun kereta api Tarahan. Kemudian rangkaian ditarik dengan menggunakan lokomotif khusus untuk membawa rangkaian menuju ke tempat pembongkaran. Proses pembongkaran gerbong batubara dilakukan dengan menggunakan alat pelabuhan utama (APU) yang disebut rotary car dumper (RCD), terdapat 4 (empat) RCD di pelabuhan Tarahan, dan diantaranya adalah RCD 3 yang memiliki double rotary car dumper dimana alat ini dapat langsung membongkar 2 (dua) gerbong sekaligus dalam sekali proses pembongkaran. Terdapat beberapa unit yang terdapat pada RCD diantaranya positioner arm, wheel gripper, dumper dan afron feeder. Alat ini beroperasi secara otomatis dimana tugas operator adalah mengawasi kerja tiap unit selama proses pembongkaran. Sistem pembongkaran dimulai dari apron feeder, belt feeder 5A, conveyor 501A, quadroll crusher 5A, conveyor 502A, Conveyor 503A dan kemudian ditampung di stockpile 4A. Untuk memulai sistem pembongkaran, operator RCD 3 akan berkoordinasi dengan operator port control center (PCC).

RCD 3 memiliki desain kapasitas sebesar 3.000 ton/jam dan satu rangkaian memiliki kapasitas muatan 50 ton tiap gerbong dengan jumlah gerbong sebanyak 60 gerbong. Sehingga proses pembongkaran untuk satu rangkaian dapat diselesaikan dalam waktu 60 menit. Untuk mengetahui proses pengoperasian alat RCD dan mengetahui serta mengetahui waktu edar alat RCD ini, maka perlu dilakukan sebuah penelitian. Terlebih lagi alat RCD ini merupakan teknologi yang cukup modern terutama di dunia pertambangan batubara di Indonesia.

\subsection{Batasan Masalah}

Batasan masalah yang diangkat dalam penelitian ini, yaitu mengidentifikasi jenisjenis trouble yang terdapat pada alat rotary car dumper (RCD), penyebab trouble dan troubleshooting yang ada, serta menghitung cycle time dan waktu pembongkaran satu rangkaian batubara.

\subsection{Tujuan Penelitian}

Tujuan dari penelitian ini adalah:

1. Mengidentifikasi trouble yang terdapat pada alat rotary car dumper (RCD) 3 di PT Bukit Asam, Tbk. Unit Pelabuhan Tarahan.

2. Menganalisa penyebab troubles dan troubleshooting yang terdapat pada alat rotary car dumper (RCD) di PT Bukit Asam, Tbk. Unit Pelabuhan Tarahan.

3. Menghitung cycle time dan waktu pembongkaran satu rangkaian batubara pada alat rotary car dumper (RCD) di PT Bukit Asam, Tbk. Unit Pelabuhan Tarahan.

\section{TEORI DASAR}

\subsection{Rotary Car Dumper 3}

Rotary Car Dumper atau RCD 3 merupakan salah satu alat pembongkaran batubara yang terdapat di PT Bukit Asam, Tbk. unit Pelabuhan Tarahan yang pembangunannya dimulai pada tahun 2013 dan merupakan produk buatan perusahaan Jerman yaitu ThyssenKrupp. RCD 3 ini dibangun untuk meningkatkan produktivitas pembongkaran di unit Pelabuhan Tarahan karena seiring juga dengan peningkatan produksi di tambang Tanjung Enim. RCD 3 memiliki 2 (dua) dumper sehingga dapat melakukan pembongkaran dua gerbong sekaligus dalam satu kali proses pembongkaran. Alat ini dioperasikan secara otomatis mulai dari awal sampai akhir proses pembongkaran, sehingga tugas operator hanya mengawasi dan mengontrol kelancaran selama proses pembongkaran. Selain itu, RCD 3 ini memiliki kapasitas bongkaran sebesar 3.000 ton/jam (spesifikasi alat), sehingga dapat melakukan pembongkaran satu rangkaian kereta dengan waktu 60 menit. Secara teori, 
satu kali proses pembongkaran membutuhkan waktu sekitar 2 menit, akan tetapi secara aktual dapat mencapai 2,5 sampai 3 menit sehingga untuk membongkar satu rangkaian membutuhkan waktu sekitar 90 menit.

Langkah-langkah yang perlu dilakukan untuk melakukan proses pembongkaran batubara antara lain:

1. Koordinasikan rangkaian batubara yang akan masuk ke area rotary car dumper untuk dilakukan pembongkaran dan minta informasi kepada satuan kerja Angkutan Batubara (angbat) mengenai nomor ID rangkaian, jumlah gerbong, jenis batubara dan jam tiba di stasiun.

2. Informasikan kepada satuan kerja Kendali Kualitas (quality control) untuk tujuan dimana batubara akan dibongkar dan ditumpuk.

3. Informasikan kepada supervisor bahwa akan ada rangkaian masuk. Ini bertujuan agar supervisor mempersiapkan sistem agar aman dan siap untuk dioperasikan. Setelah itu informasikan kepada port control center (PCC) untuk memulai sistem pembongkaran.

4. Operator turun dari kabin untuk melihat dan memastikan area RCD aman untuk dimasukkan rangkaian batubara, seperti menginformasikan kepada petugas pengambil sampah di atas gerbong, petugas kebersihan di area RCD dan tim troubleshooting yang melakukan pengecekan.

5. Informasikan kepada petugas lansir bahwa kondisi alat dan area kerja sudah aman untuk dimasukkan rangkaian batubara, serta minta petugas lansir untuk menghidupkan sirine atau terompet sebelum memasuki area kerja PT Bukit Asam, Tbk. sebagai tanda bahwa akan ada kereta rangkaian yang akan lewat.

6. Setelah rangkaian sudah tiba di area rotary car dumper, parkirkan rangkaian dengan gerbong pertama pas sebelum masuk ke dalam dumper, kemudian kunci roda gerbong dengan mengaktifkan wheel grippers. Selanjutnya minta petugas lansir untuk memutus rangkaian dari lokomotif.
7. Biarkan lokomotif yang sudah terputus menjauh sampai kira-kira jarak 10 gerbong, kemudian lanjut dengan operasi pembongkaran.

8. Pertama yaitu input jumlah gerbong ke dalam komputer, klik reset agar nilai jumlah gerbong yang dibongkar menjadi 0 (nol), pilih menu settings, pilih dan klik Start Positioner step 1 (positioner akan berjalan kearah belakang untuk menarik dua gerbong pertama), pilih dan klik start positioner step 2 (main arm akan turun ke sambungan antar gerbong) dan terakhir klik dua kali start automatic dumping, maka pembongkaran rangkaian batubara akan berjalan secara otomatis sampai gerbong terakhir.

\subsection{Bagian-bagian Rotary Car Dumper 3}

Rotary car dumper merupakan suatu kesatuan alat yang terdiri dari beberapa bagian-bagian yang memiliki fungsi-fungsi tersendiri. Bagian-bagian tersebut meliputi dumper, positioner arm, wheel grippers dan apron feeder.

\section{a. Dumper}

Dumper adalah unit yang berfungsi untuk menumpahkan batubara dari gerbong batubara dengan cara diputar sampai dengan 160 derajat dan sampai semua material batubara di gerbong habis terbuang ke apron feeder. Unit ini digerakan oleh motor listrik dan terdapat unit vertical wagon holding dan horizontal wagon holding yang keduanya berfungsi untuk menjepit dan meluruskan gerbong kereta yang ada di dumper agar tidak terjadi pergerakan saat gerbong diputar untuk menumpahkan batubara.

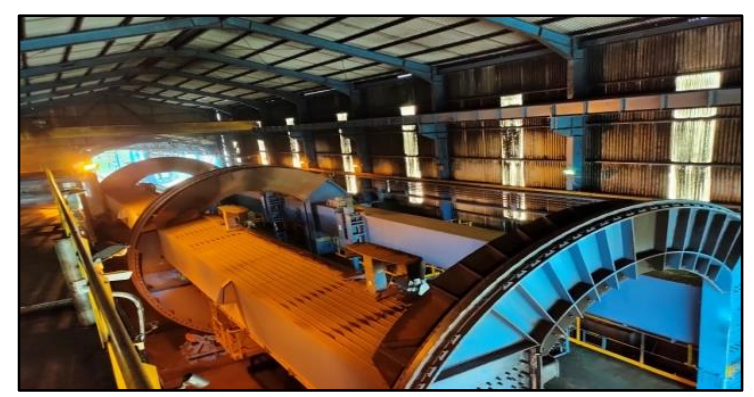

Gambar 2.1 Dumper RCD 3 
Pada unit ini terdapat sensor untuk mengindikasikan bahwa posisi gerbong tepat di dalam dumper. Agar pada saat dumper memutar, tidak terjadi tabrakan ataupun halhal yang tidak diinginkan yang menyebabkan terhambatnya operasional alat. Dumper memiliki kapasitas pembongkaran 50 ton, sehingga dalam satu kali proses pembongkaran dapat membongkar sebanyak 100 ton.

b. Positioner arm

Merupakan unit alat yang berfungsi untuk menarik rangkaian gerbong batubara setelah terlepas dari lokomotif. Pada RCD 3 terdapat dua jenis arm, yaitu main arm yang berfungsi untuk menarik gerbong rangkaian batubara mulai dari gerbong pertama sampai gerbong sebelum kedua terakhir. Auxiliary arm yang berfungsi untuk mendorong 2 (dua) gerbong terakhir. Kedua arm pada positioner ini bergerak naik dan turun menggunakan sistem hidrolik. Terdapat sensor yang berfungsi untuk mengetahui jarak yang tepat untuk arm turun ke sambungan antar gerbong. Alat ini bergerak maju dan mundur dengan menggunakan sistem roda gigi yang digerakkan oleh motor listrik dan digerakkan dengan roda gigi dimana roda gigi ini digerakkan dengan sistem hidrolik.

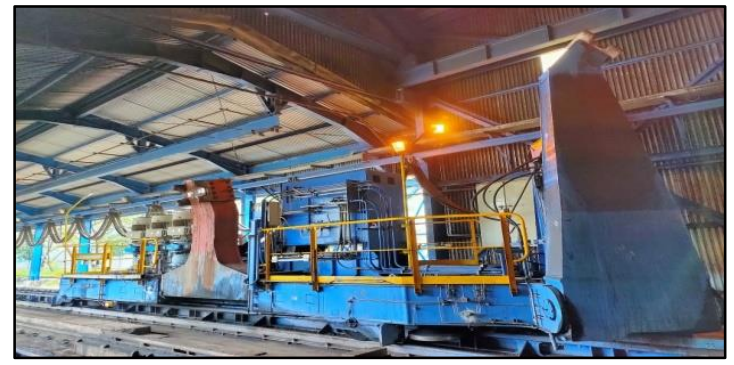

Gambar 2.2 Positioner Arm RCD 3

\section{c. Wheel grippers}

Adalah unit yang berfungsi untuk mengunci roda gerbong bagian luar dumper dengan cara dijepit agar tidak terjadi pergerakan pada saat proses pembongkaran tidak terjadi gerakan yang tidak diinginkan. Terdapat 2 (dua) unit wheel gripper, yaitu bagian sebelum masuk ke dumper (entry) dan bagian keluar dari dumper (exit).

d. Apron feeder
Merupakan alat yang bergerak memutar seperti rantai berfungsi untuk menghantarkan batubara menuju ke belt feeder, terbuat dari besi baja guna untuk menahan benturan pada saat batubara ditumpahkan oleh dumper. Pada RCD 3 terdapat dua unit apron feeder dan saling berjalan menuju posisi tengah. Di dalam apron feeder terdapat sensor yang mengindikasikan persentase dari batubara yang tertampung di dalamnya.

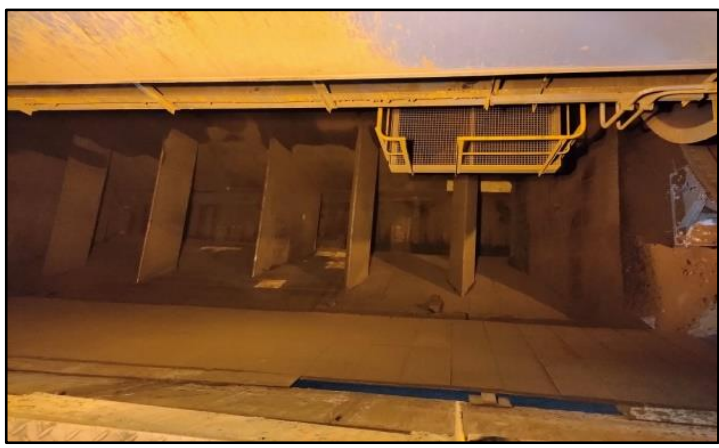

Gambar 2.3 Apron Feeder RCD 3

Dumper akan menumpahkan batubara secara otomatis apabila indikasi persentase pada apron feeder di bawah nilai $30 \%$. Hal ini berfungsi untuk mencegah terjadinya penumpukan batubara yang tidak diinginkan pada apron feeder (overload). Unit ini memiliki loading capacity sebear 1.500 ton/jam. Pada unit apron feeder ini terdapat sekat-sekat yang berfungsi untuk membagi tumpukan batubara setelah ditumpahkan oleh dumper agar mengurangi beban kerja dari apron feeder itu sendiri. Terdapat alat spillage conveyor yang terletak di bawah dari apron feeder. Alat ini berfungsi untuk membersihkan material-material sisa.

\subsection{Sistem Pembongkaran Batubara pada RCD 3 dengan mode 1}

Sistem pembongkaran dengan mode ini dimulai dari RCD sampai menuju ke Stockpile. Adapun sistem yang digunakan adalah sebagai berikut :

a. Belt Feeder 5A

Merupakan conveyor belt pertama setelah apron feeder yang memiliki kapasitas 3.300 ton/jam dengan panjang belt 14 meter. Conveyor ini digunakan untuk mentransfer 
batubara dari apron feeder menuju conveyor belt $501 \mathrm{~A}$

\section{b. Conveyor Belt 501A}

Ban berjalan yang memiliki panjang 222,5 meter dengan kapasitas belt 3.300 ton/jam. Pada conveyor ini terdapat perangkat yang berfungsi untuk mengetahui muatan batubara atau loading rate pada belt yang sedang beroperasi. Selain itu, pada ujung belt terdapat magnet yang berfungsi untuk menangkap material logam yang terdapat pada tumpukan batubara yang terdapat pada conveyor belt sebelum masuk ke crusher dan tidak mengganggu tumpukkan dari batubara di stockpile dan sampai ke konsumen.

\section{c. Quadroll Crusher 5A}

Alat ini berfungsi untuk mereduksi ukuran batubara. Terdapat 4 (empat) motor penggerak, yaitu 2 primary dan 2 secondary. Motor primary ukuran butir batubara yang dihasilkan adalah $50 \mathrm{~mm}$. Sedangkan pada secondary ukuran yang dihasilkan adalah 32 $\mathrm{mm}$.

\section{d. Conveyor Belt $502 \mathrm{~A}$}

Adalah conveyor yang sudah menerima hasil dari batubara yang sudah direduksi oleh quadroll crusher. Memiliki kapasitas belt 3.300 ton/jam dengan panjang belt 32,5 meter. e. Conveyor Belt 503A

Merupakan conveyor belt terakhir sebelum sampai ke stockpile, memiliki kapasitas 3.300 ton/jam dengan panjang belt 506,5 meter. Pada conveyor ini terdapat tripper car yang dapat bergerak maju mundur dan mengarahkan curahan batubara agar mudah untuk ditumpuk dan dibagi sesuai dengan jenis dan kualitasnya. Selain menggunakan tripper car, untuk meratakan dan menyebarkan tumpukkan batubara, digunakan juga alat penunjang pertambangan, yaitu bulldozer untuk mendorong tumpukkan batubara agar tidak terlalu tinggi

\section{f. Stockpile 4A}

Merupakan tempat untuk menumpuk batubara sementara sebelum dikirim ke konsumen melalui tongkang atau kapal. Memiliki kapasitas muat sebesar 150.000 ton. Pada stockpile ini terdapat 5 (lima) jenis tumpukan batubara yang berbeda sesuai dengan kualitasnya. Selain menggunakan tripper car, untuk merapikan tumpukan batubara yang ada agar tidak terjadi penumpukkan yang terlalu tinggi, juga menggunakan alat berat bulldozer.

\subsection{Cycle Time (Waktu Edar)}

Waktu edar adalah waktu yang diperlukan oleh suatu alat untuk melakukan suatu siklus kerja. Waktu edar alat gali muat terdiri dari waktu menggali, swing isi, loading dan swing kosong. Waktu edar yang diperoleh setiap unit alat mekanis berbeda, hal ini disebabkan oleh beberapa faktor, yaitu :

1. Kondisi tempat kerja

2. Kekerasan material

3. Keadaan jalan angkut

4. Metode pemuatan

Waktu siklus atau alat dapat didefinisikan sebagai waktu yang diperlukan oleh suatu alat untuk bekerja (beroperasi) dalam satu kali putaran. Waktu siklus untuk setiap alat tidak sama tergantung jenis alat yang digunakan serta sifat dan jenis material yang ditangani. Semakin kecil waktu siklus suatu alat, maka produksinya semakin tinggi (Prof. Ir. Partanto. P 1990).

Pada rotary car dumper, waktu edar dihitung mulai pada saat positioner mendorong gerbong, dumping dan return. Karena alat ini bersifat pasif, hanya beroperasi saat ada kereta rangkaian masuk maka perhitungan waktu edar hanya pada saat proses pembongkaran batubara berlangsung. Perhitungan cycle time pada alat rotary car dumper 3 ini dipengaruhi antara lain :

\section{Sensor dumper}

Sensor dumper sangat mempengaruhi waktu bongkaran, karena dumper akan menumpahkan batubara pada gerbong jika indikasi sensor apron feeder di bawah $30 \%$.

2. Keadaan permukaan gerbong

Pada permukaan gerbong yang basah, maka sensor positioner akan mengalami pemantulan dan pembiasan, sehingga mempengaruhi lama waktu pembongkaran untuk perbaikannya.

3. Faktor lain-lain 
Selain dua faktor di atas, terdapat faktor lain-lain diantaranya pembersihan sampah di gerbong, perbaikan kecil, penambahan oli atau grease dan penyeberangan alat yang melewati rel kereta api.

\section{METODOLOGI PENELITIAN}

\subsection{Jenis Penelitian}

Penelitian ini dilakukan dengan metode deskriptif dengan berbentuk kuantitatif dan kualitatif.

\subsection{Tempat dan Waktu Penelitian}

Penelitian ini bertempat di PT Bukit Asam, Tbk. yang berada di Jalan Soekarno Hatta KM 15 Tarahan, Kota Bandar Lampung, Provinsi Lampung. Penelitian ini dilaksanakan pada tanggal 1 April sampai dengan 1 Mei 2021.

\subsection{Metode Penelitian}

Metode penelitian yang digunakan dalam penelitian ini antara lain:

1. Cara pengambilan data

Metode pengambilan data penelitian yang digunakan:

a. Studi literatur

Studi literatur dilakukan dengan mencari studi pustaka serta teori yang berhubungan dengan penelitian ini.

b. Observasi lapangan

Observasi lapangan dilakukan dengan mengamati secara langsung aktifitas di lapangan mengenai permasalahan yang sedang terjadi.

\section{c. Wawancara}

Wawancara adalah proses untuk mendapatkan informasi yang berkaitan dengan penelitian yang didapatkan secara langsung di lapangan dari informan atau orang yang berkaitan langsung dengan objek yang diteliti.

2. Pengambilan data lapangan

Ada dua jenis data pada penelitian ini, antara lain:

a. Data primer

Data primer adalah data yang diperoleh dari kegiatan pengamatan secara langsung di lapangan, data tersebut meliputi jenis trouble yang ada di alat rotary car dumper 3 , penyebab trouble dan troubleshooting yang terjadi pada rotary car dumper 3 serta perhitunga cycle time dan lama waktu pembongkaran.

b. Data sekunder

Data sekunder adalah bagian dari data pendukung yang didapatkan dari sumbersumber yang ada sebagai data pendukung dari data primer dan tidak didapat secara langsung, Data tersebut antara lain:

a) Data spesifikasi rotary car dumper (RCD),

b) Data spesifikasi apron feeders,

c) Data spesifikasi positioner arm,

d) Data spesifikasi wheel grippers,

e) Data Spesifikasi conveyor Bbelt,

f) Data spesifikasi quadroll crusher,

g) Layout RCD 3, dan

h) Laporan pembongkaran RCD 3.

3. Pengolahan data

Data yang telah diperoleh kemudian diklasifikasikan berdasarkan jenis data kemudian dilakukan pemecahan masalah dan perhitungan serta analisis sesuai dengan kebutuhan dan tujuan penelitian ini. Mencari trouble pada rotary car dumper 3, menganalisis penyebab trouble dan troubleshooting pada rotary car dumper 3, melakukan perhitungan untuk mengetahui cycle time, dan waktu pembongkaran satu rangkaian batubara.

4. Analisis hasil pengolahan data

Data-data yang didapat kemudian dilakukan perhitungan cycle time rotary car dumper (RCD) dan troubleshooting yang ada di rotary car dumper.

5. Pembahasan

Melakukan pengkajian tentang data yang telah diolah dan menganalisa data yang sudah didapatkan melalui studi literatur, observasi lapangan dan wawancara langsung untuk dapat menyimpulkan dari apa yang telah dilaksanakan.

6. Penarikan kesimpulan

Pengambilan kesimpulan diambil dari pembahasan mengenai data yang telah dilakukan analisis sebelumnya. Kesimpulan menjadi poin penting yang akan menjadi akhir penyelesaian dari penelitian yang dilakukan.

\section{HASIL DAN PEMBAHASAN}


Dalam melakukan pengoperasian alat tentunya terdapat beberapa hal-hal yang menjadi permasalahan dan mengganggu kelancaran selama melakukan proses pengoperasiannya. Troubleshooting adalah sebuah istilah yang merujuk kepada sebuah solusi penyelesaian masalah. Pemecahan masalah merupakan mencari sumber masalah secara sistematis sehingga masalah tersebut dapat diselesaikan. Troubleshooting umumnya digunakan dalam berbagai bidang, seperti halnya dalam bidang komputer, administrasi sistem, dan juga bidang elektronika dan listrik dan kelistrikan (Aryaningsih, 2008).

\subsection{Trouble pada Rotary Car Dumper 3}

Alat rotary car dumper 3 merupakan alat yang beroperasi secara otomatis dan digerakkan oleh sistem kelistrikan, sistem hidrolik dan sensor-sensor yang memiliki sensitifitas cukup tinggi. Oleh karena itu, di dalam pengoperasiannya pasti terdapat troubles atau permasalahan-permasalahan yang terjadi, antara lain :

1. Masalah kelistrikan (emergency stop relay trip)

Saat terjadi halangan dengan indikasi emergency stop relay trip, maka yang harus dilakukan oleh seorang operator rotary car dumper 3 adalah menginformasikan kepada tim troubleshooting listrik untuk me-reset dan melihat halangan yang terjadi. Indikasi ini dapat diketahui dengan berhentinya proses pembongkaran dan indikasi dapat dilihat di layar komputer pada cabin operator. Indikasi ini biasanya muncul pada saat panel listrik dalam keadaan panas selama berjalannya Indikasi ini biasanya muncul pada saat panel listrik dalam keadaan panas selama berjalannya operasi pembongkaran.

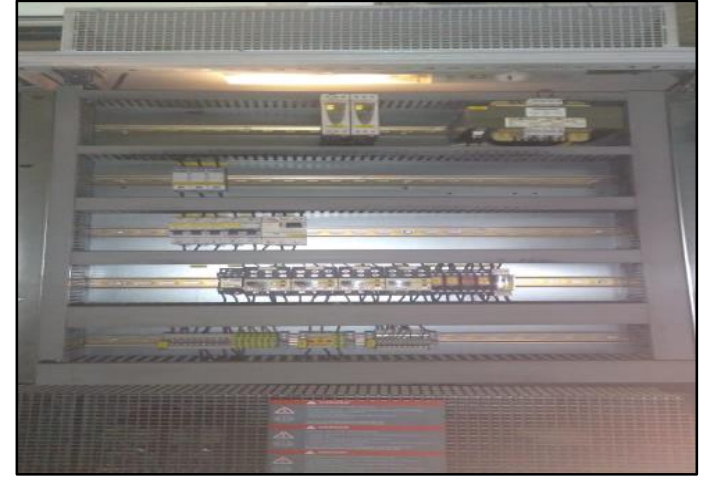

Gambar 4.1 Panel Listrik Emergency Stop Relay Trip

Oleh sebab itu, untuk mencegah terjadinya indikasi ini yang berulang, maka sebaiknya diberikan pendingin atau air conditioner (AC) pada ruangan panel listrik. Karena untuk proses melakukan reset indikasi ini diperlukan waktu 5-10 menit dan mengganggu waktu pembongkaran. Hal ini terjadi karena posisi tim troubleshooting yang cukup jauh, dapat juga di reset dengan watu cepat, jika ada yang berjaga atau sedang berada di sekitar area rotary car dumper 3 .

2. Sensor indikasi apron feeders yang terhalang debu

Pada musim kemarau biasanya bongkaran batubara terlalu kering sehingga menyebabkan banyak debu. Jika muatan debu terlalu banyak, dapat mengacaukan pembacaan sensor pada muatan batubara yang ada di apron feeders. Sensor dumper memiliki sensitifitas yang cukup tinggi terhadap debu yang beterbangan di atas permukaan apron feeder sehingga mempengaruhi dumper yang akan membongkar gerbong batubara.

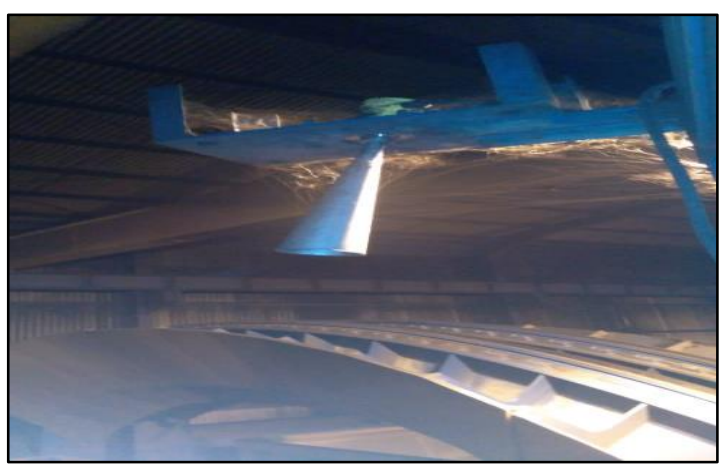

Gambar 4.2 Sensor Indikasi Apron Feeders 
Indikasi ini dapat diketahui saat persentase pada apron feeders tidak mau turun, sehingga menghambat waktu bongkaran dan menghabiskan waktu yang cukup lama. Hal yang perlu dilakukan jika terjadi halangan ini adalah mengurangi intensitas debu dengan cara menghidupkan waterspray yang terdapat diatas gerbong sebelum masuk ke dumper. Selain itu, terdapat waterspray pada bagian dinding atas apron feeder yang dapat dihidupkan untuk mengurangi debu pada saat proses menumpahkan batubara dari gerbong ke apron feeder.

\section{Positioner berhenti tidak pada tempatnya}

Sensor positioner sangat sensitif terhadap permukaan yang basah atau mengkilap yang sifatnya dapat memantulkan cahaya, karena sensor ini menggunakan sinar laser. Positioner akan berhenti pada tempat yang tidak sesuai dikarenakan pembacaan sensor yang error akibat sinar laser yang mengalami pembiasan dan pemantulan pada permukaan gerbong yang basah akibat hujan ataupun gerbong yang terkena air dari water spray karena batubara berdebu dan juga permukaan gerbong yang mengkilap dikarenakan kesalahan PT Kereta Api pada saat pengecatan permukaan gerbong. Untuk mengatasi trouble ini diperlukan waktu antara 10-15 menit, karena power mesin harus dimatikan terlebih dahulu dan diubah ke posisi manual operation kemudian positioner digerakkan secara manual oleh operator dengan dibantu oleh asisten operator. Setelah pada posisi yang sesuai, maka proses pembongkaran dapat dilanjut dengan sistem otomatis kembali. Trouble ini dapat terjadi berulang, biasanya operator menempatkan seorang asisten untuk memainkan sensor yang ada di positioner arm.

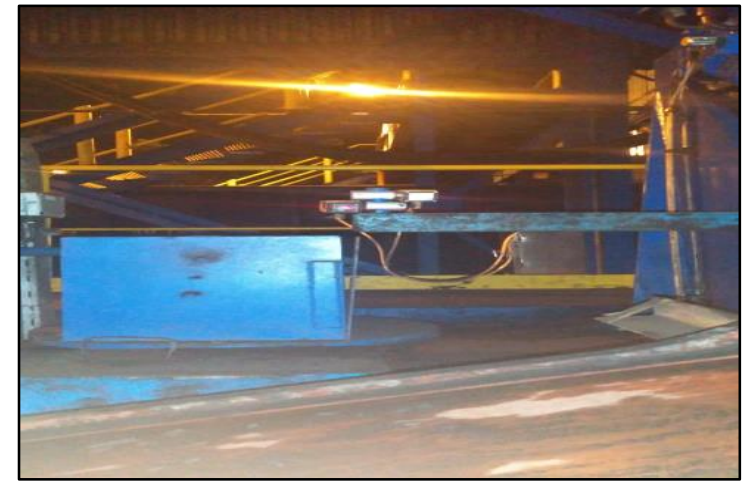

Gambar 4.3 Sensor Positioner RCD 3

4. Tunggu pengambilan sampah di gerbong

Hal ini biasanya terjadi jika terdapat sampah yang terlalu banyak dan perlu waktu yang cukup lama untuk membersihkannya, sehingga proses pembongkaran harus berhenti sementara. Kegiatan ini dilakukan oleh petugas pengambil sampah (hand picking) yang berada sebelum memasuki area rotary car dumper 3.

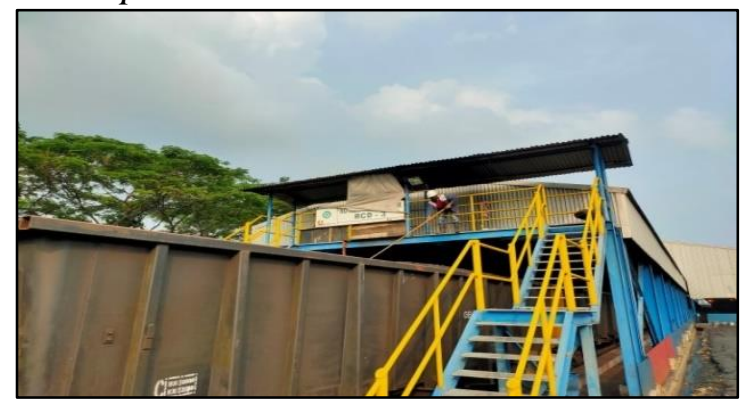

Gambar 4.4 Proses Pengambilan Sampah di Gerbong

Permasalahan ini dapat dihilangkan apabila kebiasaan orang-orang yang bertempat tinggal di tepi rel kereta api tertib membuang sampah pada tempatnya dan tidak membuang sampah sembarangan terutama menjadikan gerbong kereta sebagai tempat pembuangan sampah.

\subsection{Cycle Time Rotary Car Dumper 3}

Untuk mengetahui standar waktu yang diperlukan untuk melakukan pembongkaran rangkaian batubara, maka perlu diketahui cycle time (waktu edar). Cycle time pada alat rotary car dumper 3 dimulai pada saat positioner arm menarik gerbong, dumper menumpahkan batubara dan dumper return ke posisi semula. Cycle time pada alat ini dipengaruhi oleh indikasi sensor yang ada di apron feeder 
Dari data dapat diketahui rata-rata waktu satu kali proses pembongkaran adalah 2 menit 54 detik. Sehingga untuk satu rangkaian bongkaran batubara berjumlah 60 gerbong memerlukan waktu sekitar 5.220 detik atau 87 menit. Waktu tersebut masih sangat baik dikarenakan SOP (Standar Operasional Prosedur) waktu bongkaran sesuai kesepakatan dengan PT Kereta Api untuk tiap satu rangkaian bongkaran batubara dengan jumlah 60 gerbong membutuhkan waktu 120 menit.

\section{KESIMPULAN DAN SARAN 5.1 Kesimpulan}

Berdasarkan hasil penelitian yang dilakukan, dapat ditarik kesimpulan sebagai berikut :

1. Trouble yang sering terjadi pada rotary car dumper 3 adalah masalah kelistrikan (emergency stop relay trip), sensor indikasi apron feeders yang terhalang debu, positioner berhenti tidak pada tempatnya dan tunggu pengambilan sampah di gerbong.

2. Penyebab dan cara mengatasi trouble yang terjadi di rotary car dumper 3 antara lain :

a. Masalah kelistrikan (emergency stop relay trip) yang diakibatkan panel listrik terlalu panas dan dapat diatasi dengan memberikan pendingin ruangan pada ruangan panel listrik.

b. Sensor indikasi apron feeders yang terhalang debu yang diakibatkan bongkaran terlalu banyak debu dan dapat diatasi dengan pemberian air menggunakan water spray.

c. Positioner berhenti tidak pada tempatnya yang diakibatkan sensor yang error karena pembiasan dan pemantulan terhadap permukaan gerbong yang basah dan dapat diatasi secara manual dengan menempatkan asisten operator di unit tersebut.

d. Tunggu pengambilan sampah di gerbong yang diakibatkan terlalu banyak sampah didalam gerbong dan dapat diatasi secara manual oleh petugas handpicking.

3. Waktu edar pada RCD, yaitu 2 menit 54 detik satu kali proses bongkar, dan membutuhkan waktu 87 menit untuk satu kali proses pembongkaran satu rangkaian batubara.

\subsection{Saran}

Untuk menghindari terjadinya trouble pada alat rotary car dumper 3, sebaiknya dilakukan koordinasi dengan satuan kerja di Tanjung Enim untuk mengetahui kodisi batubara yang akan dikirimkan, melakukan koordinasi kepada pihak kereta api untuk melakukan pembersihan gerbong sebelum masuk area rotary car dumper 3 dan selalu melakukan pengecekan terhadap kondisi alat sebelum dioperasikan.

\section{DAFTAR PUSTAKA}

Anisari, Rezky. 2012. Keserasian Alat Muat dan Angkut untuk Kecapaian Target Produksi Pengupasan Batuan Penutup Pada PT Unirich Mega Persada Site Hajak Kabupaten Barito Utara Kalimantan Tengah. Jurnal INTEKNA Tahun XII. 1 (12). hlm 24.

Indonesianyo, Y. 2014. Pemindahan Tanah Mekanis. Yogyakarta: Seri Tambang Umum. 
IMI IEMIII Volume 12 No.02 Desember 2021 